\title{
Obtaining targeted metagenomes from uncultivated environmental Synechococcus using flow cytometry-based viral tagging
}

Matthew B. Sullivan ( $\triangle$ mbsulli@email.arizona.edu )

Departments of Ecology and Evolutionary Biology, and Molecular and Cellular Biology, University of Arizona, Tucson, Arizona, 85721, USA

\section{Li Deng}

Department of Ecology and Evolutionary Biology, University of Arizona, Tucson, Arizona, 85721, USA

\section{Bonnie T. Poulos}

Department of Ecology and Evolutionary Biology, University of Arizona, Tucson, Arizona, 85721, USA

\section{Method Article}

Keywords: Cyanophage, Uncultivated, Flow cytometry, Viral tagging

Posted Date: October 31st, 2014

DOI: https://doi.org/10.1038/protex.2014.041

License: (c) (1) This work is licensed under a Creative Commons Attribution 4.0 International License. Read Full License 


\section{Abstract}

Ocean viruses are abundant, ubiquitous, and play important roles in global biogeochemical cycles through mortality, horizontal gene transfer and manipulation of host metabolism. However, the ability to link viruses to their hosts in a high-throughput manner bottlenecks our ability to understand virus-host interactions in complex communities. Here, we present viral tagging $\backslash(\mathrm{VT})$, a method that combines mixtures of isotope labeled host cells and fluorescent viruses with flow cytometry. In a single experiment, we can screen $10^{7}$ uncultivated ocean viruses with a single strain of _Synechococcus_. These viruses can then be sequenced to quantitatively link objectively defined environmental viral populations, and their genomes, to their hosts.

\section{Introduction}

As ocean ecology attempts to advance from observations to predictions, modeling becomes of fundamental importance. While two decades of viral ecology research has focused on community level understanding through measuring viral abundance, production, decay, and frequency of infected cells $\backslash$ (_reviewed by Ref ${ }^{1}$ )), little is known about the fundamental question of "who infects whom?". Cultivation-based methods can directly link a virus strain to its host; however, it is impossible to characterize millions of viruses per milliliter of seawater and thousands to 100s of thousands of "viral types" per sampling site ${ }^{2}$ using traditional low-throughput cultivation methods. For example, Fluorescently Labeled Viruses $\backslash$ (FLVs) have been used as probes to "tag" their host cells for examination under the microscope $\mathrm{e}^{3-5}$, a method that is limited only by being low-throughput. Here, as illustrated in Fig 1 , we expand upon the use of FLVs to tag host cells by $\backslash\left({ }_{-} i_{-}\right)$incorporating flow cytometry to enable highthroughput detection and sequencing of infected host cells, and $\backslash$ (_ii_) isotope labeling host cells to minimize the bacterial DNA in the viral tagging metagenome. See figure in Figures section. ${ }^{\star \star}$ Figure 1. Overview for viral tagging $\backslash(\mathrm{VT})^{\star \star * \star} \mathrm{A}$. ${ }^{* \star}$ Environmental viruses are fluorescently-labeled green, then mixed with potential host bacteria which are labeled with heavy isotope, but flow cytometrically greennegative. ${ }^{*} \mathrm{~B}$. ${ }^{* \star}$ Flow cytometry data triggered on forward scatter for the fluorescently labeled virus and host bacteria co-incubated at desire VBR. Tagged cells infecting by viruses with extra fluorescence can be sorted out from non-infected cells. ${ }^{* \star} \mathrm{C} .{ }^{\star \star}$ DNA is extracted from the sorted, viral-tagged population. Isotopically light viral DNA is then separated from heavy host DNA using a density gradient for the downstream amplification and sequencing.

\section{Reagents}

1. ${ }^{15} \mathrm{~N}$ ammonium chloride $\backslash($ Cambridge Isotope Laboratories, Inc. NLM-467-1). 2. Quant-iT Pico Green \ (Invitrogen P7589). 3. SYBR Gold \(Invitrogen S11494). 4. TE buffer \(10mM Tris, $1 \mathrm{mM}$ EDTA). 5. MTN buffer $\backslash(0.6 \mathrm{M} \mathrm{NaCl}, 0.1 \mathrm{M}$ Tris-Cl pH 7.5, 0.1 M MgCl 2$)$. 6. Bovine serum albumin $\backslash(\mathrm{BSA})$. 7. Phosphate buffered saline $\backslash\left(\right.$ PBS). 8. Fluorescent polystyrene FLOW Check $^{\text {TM }}$ microspheres $\backslash(1 \mu \mathrm{m}$ yellow-green beads; Polysciences Inc., PA, cat\# 23517-10). 


\section{Equipment}

1. Ultracentrifuge, we used a Beckman L70 ultracentrifuge with Beckman VTi 65 vertical rotor and $13 \times 48$ $\mathrm{mm}$ OptiSeal polyallomer tubes $\backslash(4.9 \mathrm{ml}$ capacity). 2. Appliskan plate reader $\backslash($ Thermo Electron, Vantaa, Finland). 3. Sonication bath, we used VWR Signature Ultrasonic cleaner B1500A-DTH. 4. Refrigerated centrifuge, we used Eppendorf 5417R. 5. Flow cytometer, we used iCyt Reflection flow cytometer $\backslash$ (Sony Biotechnology) and a MoFlo ${ }^{\text {TM }}$ XDP cytometer $\backslash($ Beckman Coulter). 6. Nanosep 10K centrifugal tubes $\backslash$ (Pall OD010C33).

\section{Procedure}

**|sotopic Labeling of Cyanobacteria and DNA Analysis** 1. Prepare SNAX medium according to directions ${ }^{6}$, but use ${ }^{15} \mathrm{~N}$ ammonium chloride which will provide the heavy isotope. Grow cyanobacteria in the medium with heavy nitrogen and transfer at least 3 times before use. 2. Extract DNA from bacterial grown in heavy nitrogen using standard methods. 3. Quantify the DNA using Quant-iT Pico Green $\backslash$ (Invitrogen \#P7589). 4. Use at least $10 \mu \mathrm{g}$ of DNA for density gradient centrifugation. 5. For density gradient centrifugation, a Beckman VTi 65 vertical rotor was used with $13 \times 48 \mathrm{~mm}$ OptiSeal polyallomer tubes $\backslash(4.9 \mathrm{ml}$ capacity). 6 . Mix the DNA with TE buffer $\backslash(10 \mathrm{mM}$ Tris, $1 \mathrm{mM}$ EDTA, pH7.6) to a final volume of $0.9 \mathrm{ml}$. 7. Mix the DNA with $4 \mathrm{ml}$ of $\mathrm{CsCl}$ prepared in TE to a density of p1.8 \(measure the density of the final solutions, they should be p1.7). 8. Dispense $4.9 \mathrm{ml}$ of the DNA sample in $\mathrm{CsCl}$ into the OptiSeal tube and plug with the black caps. 9. Centrifuge at $44,000 \mathrm{rpm} \backslash(=184,678.5 \mathrm{~g})$ in a Beckman L70 or L80 ultracentrifuge for $48 \mathrm{hr}$ at $18^{\circ} \mathrm{C} \backslash$ (Caution: do not centrifuge at lower temperatures as $\mathrm{CsCl}$ may precipitate out). 10. Collect $0.2-0.25 \mathrm{ml}$ fractions and measure the density of each. 11 . Calculate amount of DNA in each fraction using Quant-iT Pico Green \(perform in dulicate) to determine the density of the fractions with DNA. Estimate the ratio of isotopic labeled cells. **Preparation of SYBR Gold working stock ${ }^{\star}$ 1. Thaw $10,000 x$ stock of SYBR Gold in the dark and vortex vigorously. 2 . Centrifuge for 10 min at $3000 \mathrm{x}$ g. 3. Dilute 1:100 \(to 100x) with TE buffer and then filter through $0.02 \mu \mathrm{m}$ filter. 4 . Aliquot into 50 or $100 \mu \mathrm{l}$ amounts and store frozen at $-20^{\circ} \mathrm{C}$. ${ }^{\star \star}$ SYBR-Gold Staining of Virus ${ }^{\star \star} 1$. Thaw prepared $100 \mathrm{X}$ SYBR Gold the dark, one time only $\backslash$ (do not refreeze). 2. Vortex thawed SYBR Gold vigorously before using to stain viruses. 3. If using $\mathrm{CsCl}$-purified virus, dialyze in modified MTN buffer. 4 . Stain the viruses by adding prepared SYBR Gold to the viral suspension to a final concentration of $5 x$ for a concentrated viral stock $\backslash$ (equal to or greater than E+09) or 1x for less concentrated viral stock $\backslash(15 \mathrm{~N}$-labeled "heavy" host DNA from non-labeled "light" viral DNA by CsCl density ultracentrifugation. See "Cesium Chloride Virus Purification and Dialysis" protocol ${ }^{7}$. 10. Light DNA can be linker amplified ${ }^{8}$ for sequencing by 454 Roche Titanium and Illumina HiSeq 2000. Please note that our linker ligation step of the library prep strongly selects against ssDNA and further, RNA viruses would not be sequenced in a DNA metagenome.

\section{Timing}

The time required for isotope labeling of host cells is variable, for 3 inoculation of _Synechococcus_ WH7803 are about 3-4 weeks. The viral wash steps usually take about 3hs. The sorting takes about 
1hour for $\mathrm{E}+08$ cells, depending on the number collected and the experience of the investigator. Thus the whole procedure can be accomplished within 4-5 weeks.

\section{Troubleshooting}

1. Increase in $520 \mathrm{~nm}$ fluorescence of the mixture of cells and the SYBR-Blank. The washing procedure for the viruses is probably not adequate. 2. No increase in $520 \mathrm{~nm}$ fluorescence of the mixture of cells and the strained and washed viruses. The washing procedure for the viruses might have failed and lost most of the viruses, count the number of viruses recovered from washing. Otherwise increase the VBR to add more viruses per cell.

\section{Anticipated Results}

Following the viral tagging method and DNA isolation and extraction, resulting DNA can be sequenced and used for viral community analysis $\backslash$ (see Figure 1). See figure in Figures section. ${ }^{\star \star}$ Figure 2. Reference flow cytometry charts. ${ }^{* * *} \mathrm{~A}-\mathrm{C} .{ }^{* *}$ Reflection data of viral-tagging samples. ${ }^{* \star A}$. ${ }^{* *}$ Bacteria alone: $15 \mathrm{~N}-\mathrm{Syn}$ WH7803 ${ }^{* * B}$. ${ }^{* *}$ No viruses staining control: $15 \mathrm{~N}-\mathrm{Syn}$ WH7803 + stained and washed buffer without adding viruses. A green negative and FSC negative noise population appeared in bottom left corner of plot, negative to bacterial primers. ${ }^{*} \mathrm{C} .{ }^{\star \star}$ Viral-tagging sample 1: $15 \mathrm{~N}-\mathrm{Syn}$ WH7803 + stained and washed viruses ${ }^{* *} \mathrm{D}-\mathrm{F}$. ${ }^{* *}$ MoFlo data of viral-tagging samples. ${ }^{* *} \mathrm{D}$. ${ }^{* \star}$ Bacteria alone: $15 \mathrm{~N}-S y n$ WH7803 ${ }^{* \star} \mathrm{E}$. ${ }^{* *}$ No viruses staining control: $15 \mathrm{~N}-S y n$ WH7803 + stained and washed buffer without adding viruses. $* \star \mathrm{F}^{\star * *}$ Viral-tagging sample 1: 15N-Syn WH7803 + stained and washed viruses

\section{References}

1 Breitbart, M. in _Annual Review of Marine Science, Vol 4_ Vol. 4 _Annual Review of Marine Science_ I (eds C. A. Carlson \& S. J. Giovannoni). 425-448 \(2012). 2 Angly, F. _et al_. The marine viromes of four oceanic regions._PLoS Biol._ 4. e368 \(2006). 3 Mosier-Boss, P. A. _et al_. Use of fluorescently labeled phage in the detection and identification of bacterial species. _Appl Spectrosc._ 57, 1138-1144 \(2003). 4 Comeau, A. M. \& Noble, R. T. Preparation and application of fluorescently labeled virus particles. _S.W. Wilhelm, M.G. Weinbauer, and C.A. Suttle \[eds.]. Manual of Aquatic Viral Ecology. Waco, TX:American Society of Limnology and Oceanography.,_ 19-29 \(2010). 5 Hennes, K. P., Suttle, S. A. \& Chan, A. M. Fluorescently labeled virus probes show that natural virus populations can control the structure of marine microbial communities._Appl. Environ. Microbiol.,_61, 3623-3627 \(1995). 6 Waterbury, J. B., Watson, S. W., Valois, F. W. \& Franks, D. G. Biological and ecological characterization of the marine unicellular cyanobacterium_Synechococcus. Can. Bull. Fish. Aquat. Sci._214, 71-120 \(1986). 7 "Cesium Chloride Virus Purification and Dialysis."_Sullivan Lab Protocols._ http://www.eebweb.arizona.edu/faculty/mbsulli/protocols/ 8 "DNA Preparation and Linker Amplification."_Sullivan Lab Protocols._ http://www.eebweb.arizona.edu/faculty/mbsulli/protocols/

\section{Acknowledgements}


Funding provided by DOE JGI Community Sequencing Program, Biosphere 2, BIO5, NSF OCE0940390, and Gordon and Betty Moore Foundation grants to MBS. We thank J. Fuhrman for suggesting stableisotope-labeled host DNA; S.W. Chisholm for strains; Tucson Marine Phage Lab especially Christine L. Schirmer for technical/editorial support. We acknowledge iCyt and AZCC/ARL-Division of Biotechnology Cytometry Core Facility for cytometry support.

\section{Figures}

A
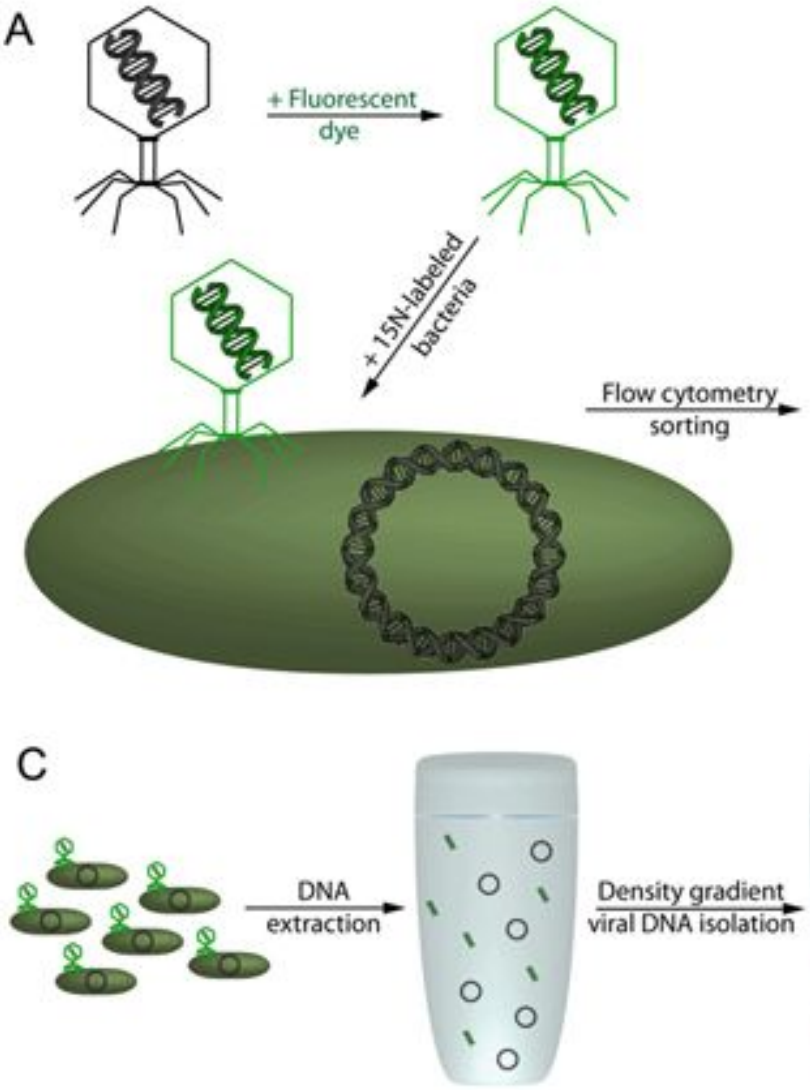

B
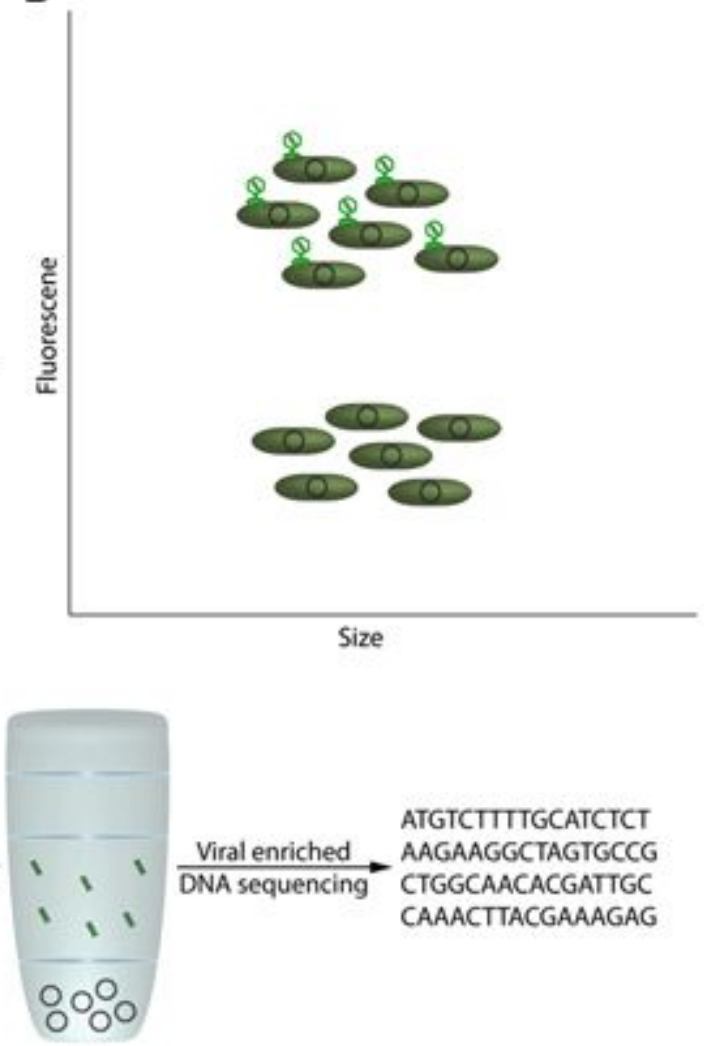

ATGTCTIITGCATCTCT

Viral enriched AAGAAGGCTAGTGCCG

$\overrightarrow{\text { DNA sequencing }}$ CTGGCAACACGATTGC

CAAACTTACGAAAGAG

\section{Figure 1}

*Overview for viral tagging $(\mathrm{VT}){ }^{\star}{ }^{*} \mathrm{~A}$. ${ }^{*}$ Environmental viruses are fluorescently-labeled green, then mixed with potential host bacteria which are labeled with heavy isotope, but flow cytometrically green-negative. *B.* Flow cytometry data triggered on forward scatter for the fluorescently labeled virus and host bacteria co-incubated at desire VBR. Tagged cells infecting by viruses with extra fluorescence can be sorted out from non-infected cells. ${ }^{*} \mathrm{C}$. ${ }^{*}$ DNA is extracted from the sorted, viral-tagged population. Isotopically light viral DNA is then separated from heavy host DNA using a density gradient for the downstream amplification and sequencing. 
A

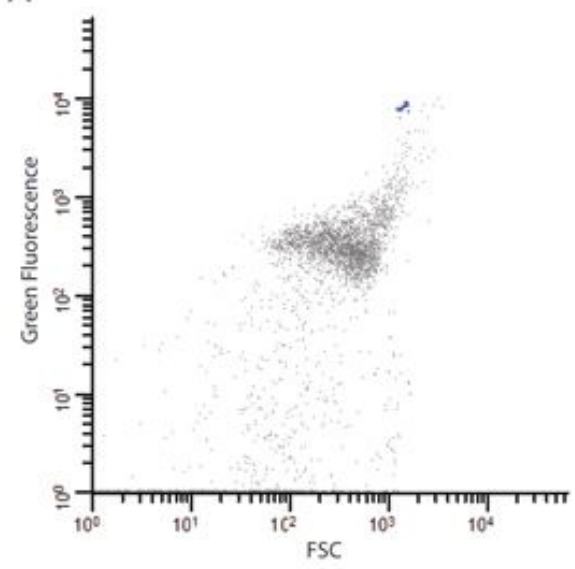

D

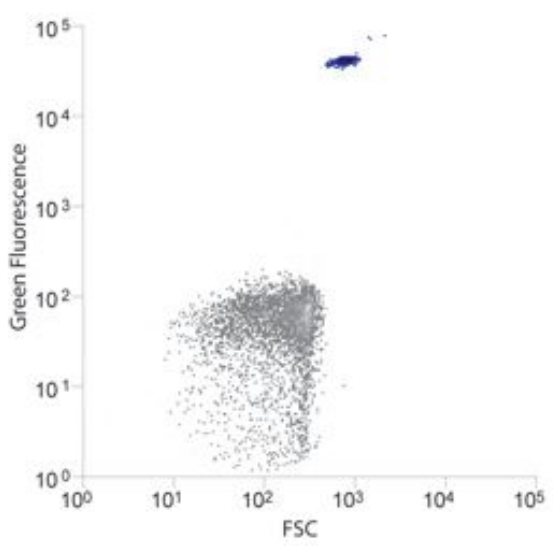

B

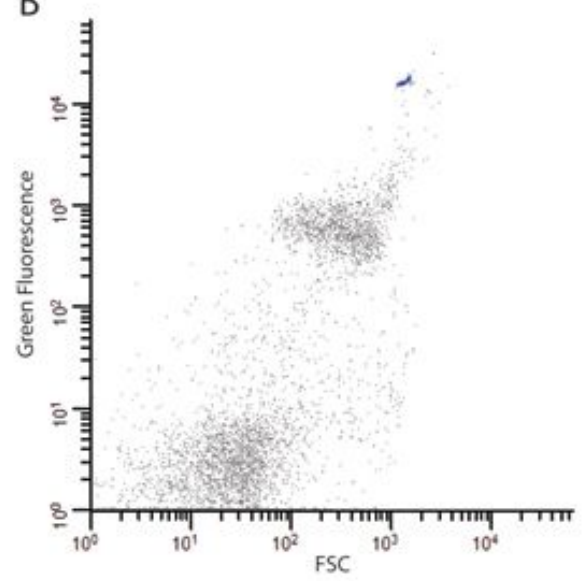

E

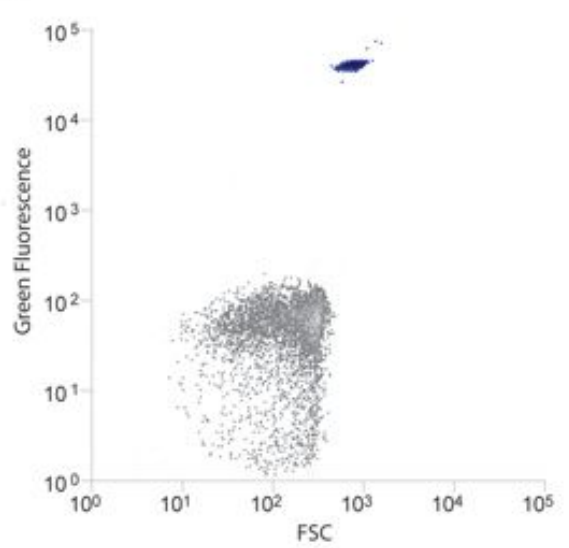

C

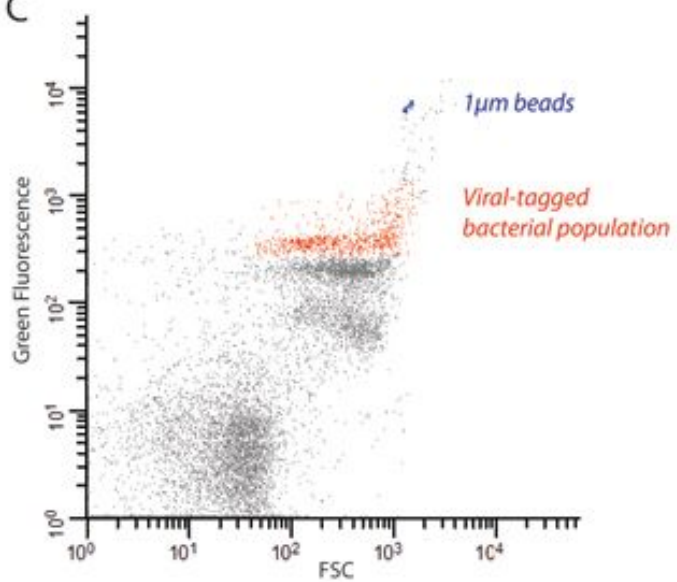

F

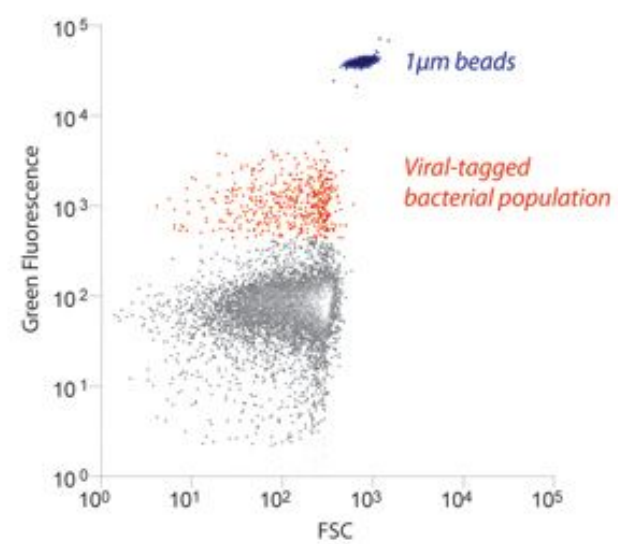

Figure 2

*Reference flow cytometry graphs* *A-C.* Reflection data of viral-tagging samples. *A.* Bacteria alone: 15N-Syn WH7803 *B.* No viruses staining control: 15N-Syn WH7803 + stained and washed buffer without adding viruses. A green negative and FSC negative noise population appeared in bottom left corner of plot, negative to bacterial primers. ${ }^{*} \mathrm{C}$ * Viral-tagging sample 1: 15N-Syn WH7803 + stained and washed viruses *D-F.* MoFlo data of viral-tagging samples. *D.* Bacteria alone: 15N-Syn WH7803 *E. ${ }^{*}$ No viruses staining control: $15 \mathrm{~N}-S y n$ WH7803 + stained and washed buffer without adding viruses. *F.* Viraltagging sample 1: 15N-Syn WH7803 + stained and washed viruses 